\title{
Tumour microvessel density as predictor of chemotherapy response in breast cancer patients
}

\section{O Tynninen ${ }^{* 1,3}$, J Sjöström ${ }^{2}$, K von Boguslawski ${ }^{3}$, NO Bengtsson ${ }^{4}$, R Heikkilä $^{5}$, P Malmström ${ }^{6}$, B Østenstad ${ }^{7}$, E Wist $^{8}$, V Valvere', E Saksela ${ }^{1,3}$, T Paavonen $^{1,3}$ and C Blomqvist ${ }^{10}$}

\begin{abstract}
'Haartman Institute, Department of Pathology, University of Helsinki, 00014 Helsinki, Finland; ${ }^{2}$ Department of Oncology, Helsinki University Central Hospital, 00029 Helsinki, Finland; ${ }^{3} \mathrm{HUCH}$ Laboratory Diagnostics, Division of Pathology, Helsinki University Central Hospital, 00029 Helsinki, Finland; ${ }^{4}$ University Hospital, S-90 I 85 Umeå, Sweden; ${ }^{5}$ Rogaland Central Hospital, N-40II Stavanger, Norway; ${ }^{6}$ University Hospital, S-21 I 85, Lund, Sweden; ${ }^{7}$ Ullevål Hospital, N-0407 Oslo, Norway; 8 University Hospital of Tromsoe, Norway; ${ }^{9}$ Estonian Cancer Centre, Tallinn EE 00 I 06, Estonia; ${ }^{10}$ University Hospital of Uppsala, S-75 85 Uppsala, Sweden
\end{abstract}

\begin{abstract}
The aim of this study was to evaluate the predictive value of intratumoural microvessel density in breast cancer. We studied immunohistochemically primary tumours of 104 patients with metastasised breast cancer who took part in a randomised multicentre trial comparing docetaxel to sequential methotrexate and 5-fluorouracil. Vessels were highlighted with factor VIII staining and counted microscopically. Microvessel density was compared with clinical response to chemotherapy and patient survival. The microvessel density of the primary tumour was not significantly associated with patient's response to chemotherapy, time to progression or overall survival in the whole patient population or in the docetaxel or methotrexate and 5 -fluorouracil groups. However, disease-free survival was longer in patients with low microvessel density $(P=0.01)$. These findings suggest that microvessel density of the primary tumour cannot be used as a predictive marker for chemotherapy response in advanced breast cancer.

British Journal of Cancer (2002) 86, 1905 - 1908. doi: I0.1038/sj.bjc.6600325 www.bjcancer.com

(c) 2002 Cancer Research UK
\end{abstract}

Keywords: microvessel density; chemotherapy; metastatic breast cancer; predictive factor

Currently most breast cancer patients suffering from metastatic disease receive chemotherapy and/or hormone therapy. Curative treatment is not yet available for metastatic breast cancer and its management is palliative in almost all cases. Chemotherapy is frequently toxic and only half of the patients with metastatic disease usually respond to the treatment. There is a need for predictive markers for chemoresistant tumours in order to avoid unnecessary side effects of chemotherapy.

Hormonal receptor status and tumour cell proliferation have been evaluated as potential predictive factors for chemotherapy (Corle et al, 1984; Willsher et al, 1998; Zambetti et al, 1999), but these tumour properties have so far shown little clinical utility. Recently many proteins including c-erbB-2, p53 and the $b c l-2$ family have been investigated as predictors for chemosensitivity (Jacquemier et al, 1994; Muss et al, 1994; Sjöström et al, 2000; Sjöström, 2002a,b). However, none of these markers have shown clinical utility in predicting response for chemotherapy in advanced breast cancer.

Immunohistochemically measured microvessel density (MVD) has been applied to quantitate the angiogenesis in breast cancer. Results from most studies suggest that tumour microvessel density is associated with lymph node metastasis and worse outcome (Weidner et al, 1991; Bosari et al, 1992; Gasparini et al, 1994;

*Correspondence: O Tynninen, HUCH Laboratory Diagnostics, Division of Pathology, Helsinki University Central Hospital 00029 Helsinki, Finland; E-mail: olli.tynninen@helsinki.fi

Received 29 November 200 I; revised 6 March 2002; accepted 27 March 2002
Toi et al, 1995; Jacquemier et al, 1998; Hansen et al, 2000) although in some studies no association was seen (Van Hoef et al, 1993; Axelsson et al, 1995; Tynninen et al, 1999; Vincent-Salomon et al, 2001). It has also been suggested that MVD may be associated to endocrine treatment response in breast cancer (Gasparini et al, 1996).

In this study we investigated whether intratumoural microvessel density is associated with response to chemotherapy in patients with metastatic breast cancer. Earlier reports on MVD as a predictive marker for chemotherapy response in advanced breast cancer have not been published.

\section{MATERIALS AND METHODS}

The patient population of the present study was a subgroup of 283 patients participating in a multicentre randomised trial comparing docetaxel with sequential methotrexate and 5-fluorouracil (MF) in advanced breast cancer (Sjöström et al, 1999). To enter the randomised study, patients were required to have histologically proven primary breast cancer that had progressed during or after first line anthracycline therapy for advanced disease or relapsed during or within 12 months after discontinuation of adjuvant anthracycline therapy. Ethical committees of all participating centres approved the study. Paraffin blocks were available for 134 patients. There was enough tumour tissue left in the blocks of 109 patients. Five patients were excluded because of excessive background staining with factor VIII antibody leaving 104 patients for final analysis (Table 1).

Formalin fixed tissue samples were embedded in paraffin. For immunohistochemistry $5 \mu \mathrm{m}$ thick sections were cut on coated 
Table I Characteristics of the primary tumour at the time of diagnosis and treatment related characteristics of the 104 investigated patients

\begin{tabular}{llcl}
\hline Factor & Subgroup & $\begin{array}{c}\text { No. of } \\
\text { patients (\%) }\end{array}$ & Median (range) \\
\hline Histology & Ductal & $96(92)$ & \\
& Lobular & $8(8)$ & \\
ER & Positive & $51(49)$ & \\
& Negative & $45(43)$ & \\
Unknown & $8(8)$ & \\
Treatment & & 104 & 1.7 years $(0-23)$ \\
& Docetaxel & $53(51)$ & \\
Response to treatment & MF & $51(49)$ & \\
Docetaxel & CR+PR & $26(52)$ & \\
MF & CR+PR & $14(27)$ & \\
TTP & & 104 & 4.1 months $(0.6-29)$ \\
OS & & 104 & 9.2 months $(0.6-36)$ \\
\hline
\end{tabular}

$E R=$ oestrogen receptor; $D F I=$ disease free survival; $C R=$ complete response; $\mathrm{PR}=$ partial response; TTP=time to progression; $\mathrm{OS}=$ overall survival.

slides. The slides were pretreated with $0.5 \%$ Trypsin and endogenous peroxidase was blocked. After rinsing the slides were incubated overnight at room temperature with diluted $(1: 10000)$ polyclonal antibody against factor VIII related antigen (von Willebrand Factor, DAKO, Glostrup, Denmark) to stain capillary endothelium. Immunoperoxidase stainings were performed using a commercial avidin-biotin detection kit (Vectastain ${ }^{\mathbb{R}}$ Elite ABC Kit, Vector Laboratories, Burlingame, CA, USA) following the manufacturer's instructions. Bound peroxidase was visualised with 3-amino-9ethylcarbazole. Finally the sections were counterstained in Mayer's haematoxylin.

Tumour microvessel density was determined from areas of highest vascularisation within invasive carcinoma. Microscopic slides were screened at low magnification $(\times 20, \times 40)$ to identify the most vascularised areas. Vessels were counted from the three most vascularised areas by one investigator ( $\mathrm{O}$ Tynninen) at a magnification of $\times 200$ (microscopic field area $0.785 \mathrm{~mm}^{2}$ ). An average of three counts reported in vessels per $\mathrm{mm}^{2}$ was used as the microvessel density of the tumour. The criteria introduced by Weidner et al (1991) were used to identify microvessels.

Response evaluation was performed according to the WHO recommendations (Miller et al, 1981). For statistical analysis clinical response was divided into two categories: response (complete and partial response) and non-response (stable disease and progression). Differences in treatment response were evaluated with the $\chi^{2}$ test in the whole patient population, and in the docetaxel and MF treated groups separately.

Disease free interval (DFI) was measured from the date of the primary diagnosis until the first recurrence of cancer, time to progression (TTP) from the date of randomisation till disease progression and overall survival (OS) from the date of randomisation till death. Kaplan-Meier plots were calculated for overall survival, disease free survival and time to progression. Differences in survival were tested with Cox logistic regression analysis with microvessel density as a continuous variable. Spearman correlation coefficients were calculated for MVD and several other previously assessed tumour related biological factors based on the same patient material and described elsewhere (Sjöström et al, 2000; Sjöström, 2002a,b). These factors included histological grade, MIB-1, expression of oestrogen receptor (ER), tumour suppressor protein $\mathrm{p} 53, \mathrm{p} 21, \mathrm{mdm}-2$, the apoptosis related proteins $b c l-2$, bax, bcl- $\mathrm{x}_{\mathrm{L}}$, bag-1, fas, fas $\mathrm{L}$ and the oncoprotein c-erbB-2. $P$ values less than 0.01 for the correlation coefficients were considered significant. In the correlative analyses the signif- icance level was set lower than the usual 0.05 because of the multiple comparisons.

\section{RESULTS}

The median microvessel density of the tumours was 95.1 vessels per $\mathrm{mm}^{2}$ (range $32.3-247.9,25$ th and 75 th percentile 74.7 and 132.4, respectively. MVD was not significantly associated with response to chemotherapy when tested in the whole patient population $(P=0.88)$ nor in separate groups of docetaxel $(P=0.13)$ or MF $(P=0.24)$ treated patients. However, low microvessel density showed a trend towards better response rate in the docetaxel arm (RR 68\% vs 40\%, Table 2). Overall survival or time to tumour progression were not associated with MVD in univariate analysis neither in the whole patient population $(P=0.75)$ nor in docetaxel $(P=0.64)$ or $\mathrm{MF}(P=0.88)$ groups. However, disease free interval from primary diagnosis to the appearance of first metastases was shorter in patients with tumour MVD above median $(P=0.01$, Figure 1).

We also assessed the correlation between MVD and other tumour biological factors previously studied in the same population (Table 3). MVD was inversely correlated with MIB-1 proliferation index $(P=0.007)$. Tumour grade did not correlate with MVD. Expression of fas ligand (fasL) was positively correlated with MVD $(P=0.002)$ but no correlation was found with any other biological factor investigated (Table 3 ).

\section{DISCUSSION}

We studied intratumoural microvessel density in 104 patients with advanced breast cancer to evaluate its predictive value for chemotherapy. We could not demonstrate any difference in response to chemotherapy, overall survival or time to progression between the patient groups according to vascular density either in the whole patient material or in the docetaxel arm. However, in the MF arm there was a trend towards better chemotherapy response in the low microvessel density group but the difference was not statistically significant. High MVD was associated with short disease free interval which is in line with several previous studies (Weidner et al, 1992; Toi et al, 1993; Hansen et al, 2000).

Preclinical studies suggest that chemoresistance might be associated with tumour vascularity (Gasparini et al, 1996). Instead of facilitating the access of chemotherapeutic agents into the tumour neovascularisation has been proposed to inhibit penetration of cytotoxic drugs into tumour tissue due to increased interstitial pressure (Folkman, 1995). Consequently, one would expect that response to chemotherapy in more vascularised tumours would be weaker compared to those with low MVD which is in accordance with our findings in the docetaxel group.

Against our expectations response to docetaxel was not related to microvessel density. Previous reports suggest that taxanes including docetaxel used in this study also harbour an anti-angiogenic effect themselves (Belotti et al, 1996; Sweeney et al, 2001). However, in the present study, the methodology to test the predictive value of MVD for response to taxanes was not optimal. MVD and other parameters were counted in the primary tumour and the measured outcome was clinical response after disease recurrence which may be a source of error because the biological properties of metastases may differ from the primary tumour.

To the best of our knowledge there are no previous report on the predictive utility of MVD for chemotherapy in advanced breast cancer. Two studies have investigated microvessel density in breast cancer patients receiving either adjuvant or neoadjuvant chemotherapy. In one study Protopapa et al (1993) demonstrated that the patients who survived longer after mastectomy and chemotherapy had higher MVD. In the other study Paulsen et al (1997) did not find any difference in the outcome according to MVD in patients treated with neoadjuvant chemotherapy. 
Table 2 Association of microvessel density and clinical response to chemotherapy in 101 patients with evaluable response to treatment

\begin{tabular}{|c|c|c|c|c|c|c|}
\hline \multirow[b]{2}{*}{ MVD (vessels per $\mathbf{~ m m}^{2}$ ) } & & \multicolumn{4}{|c|}{ Clinical response (\%) } & \multirow[b]{2}{*}{$P \chi^{2}$ test } \\
\hline & & PD & NC & PR & CR & \\
\hline All tumours & $\begin{array}{l}\text { Low }(<95.9) \\
\text { High }(\geqslant 95.9)\end{array}$ & $\begin{array}{l}32(32 / 10 \mid) \\
28(\mid 4 / 50) \\
35(|8 / 5|)\end{array}$ & $\begin{array}{l}29(29 / 101) \\
28(14 / 50) \\
29(15 / 51)\end{array}$ & $\begin{array}{ll}33 & (33 / 101) \\
34 & (17 / 50) \\
31 & (16 / 51)\end{array}$ & $\begin{array}{c}7(7 /|0|) \\
10(5 / 50) \\
4(2 / 51)\end{array}$ & 0.88 \\
\hline All tumours in docetaxel group & $\begin{array}{l}\text { Low }(<95.9) \\
\text { High }(\geqslant 95.9)\end{array}$ & $\begin{array}{r}18(9 / 50) \\
5(1 / 22) \\
29(8 / 28)\end{array}$ & $\begin{array}{l}30(15 / 50) \\
27(6 / 22) \\
32(9 / 28)\end{array}$ & $\begin{array}{l}42(21 / 50) \\
50(11 / 22) \\
36(10 / 28)\end{array}$ & $\begin{array}{r}10(5 / 50) \\
18(4 / 22) \\
4(1 / 28)\end{array}$ & 0.13 \\
\hline All tumours in MF group & $\begin{array}{l}\text { Low }(<95.9) \\
\text { High }(\geqslant 95.9)\end{array}$ & $\begin{array}{l}45(23 / 51) \\
46(13 / 28) \\
43(10 / 23)\end{array}$ & $\begin{array}{l}27(|4 / 5|) \\
29(8 / 28) \\
26(6 / 23)\end{array}$ & $\begin{array}{l}24(12 / 51) \\
21(6 / 28) \\
26(6 / 23)\end{array}$ & $\begin{array}{l}4(2 / 51) \\
4(1 / 28) \\
4(1 / 23)\end{array}$ & 0.24 \\
\hline
\end{tabular}

$M V D=$ mean microvessel density; $P D=$ progressive disease; $N C=$ no change; $P R=$ partial response; $C R=$ complete response.

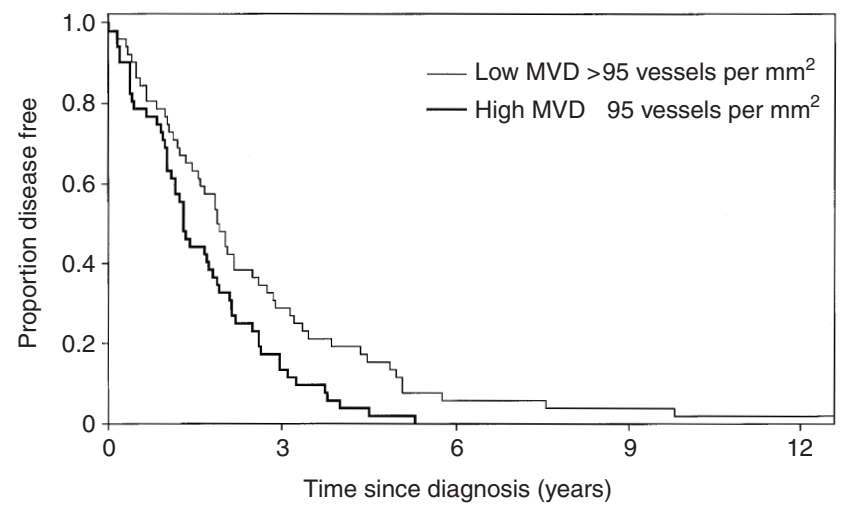

Figure I Kaplan-Meier plot showing disease free interval in 104 breast cancer patients. Disease free interval was shorter in patients with MVD above median 95 vessel per $\mathrm{mm}^{2}(P=0.01)$.

Table 3 Correlation between tumour microvessel density and other biological factors $(n=104)$

\begin{tabular}{lcl}
\hline Factor & Correlation coefficient & $\boldsymbol{P}$ \\
\hline Histological grade & 0.08 & 0.43 \\
MIB-I & -0.26 & 0.007 \\
P53 & -0.19 & 0.05 \\
P21 & 0.02 & 0.84 \\
ER & 0.18 & 0.09 \\
fas & 0.06 & 0.53 \\
fasL & 0.30 & 0.002 \\
mdm2 & 0.15 & 0.12 \\
bagl & 0.10 & 0.31 \\
bax & 0.12 & 0.23 \\
bcl-2 & 0.14 & 0.15 \\
bcl- $\mathrm{X}_{\mathrm{L}}$ & -0.03 & 0.76 \\
c-Erb-B2 & 0.01 & 0.92 \\
\hline
\end{tabular}

\section{REFERENCES}

Axelsson K, Ljung BE, Moore II D, Thor AD, Chew KL, Edgerton SM, Smith HS, Mayall BH (1995) Tumor angiogenesis as a prognostic assay for invasive ductal breast carcinoma. J Natl Cancer Inst 87: $997-1008$

Belotti D, Vergani V, Drudis T, Borsotti P, Pitelli MR, Viale G, Giavazzi R, Taraboletti G (1996) The microtubule-affecting drug paclitaxel has antiangiogenic activity. Clin Cancer Res 2: $1843-1849$
We also tested correlations between microvessel density and several other tumour biological factors (histological grade, MIB-1, ER, p53, p21, mdm-2, bcl-2, bax, bcl- $\mathrm{x}_{\mathrm{L}}$, bag-1, fas, fasL and c-erbB-2). Only two significant correlations were seen. We noted an inverse correlation between MVD and MIB-1 proliferation which is in line with the recent findings by another group (Medri et al, 2000). However, most studies have not found significant association between MVD and MIB-1 proliferation index (Weidner et al, 1992; Vartanian and Weidner, 1994; Jacquemier et al, 1998; Tynninen et al, 1999).

The positive correlation between vascular density and fas ligand expression was particularly interesting. The fas receptor belongs to the family of tumour necrosis factor related death receptors and fasL is its corresponding ligand. Binding of a death ligand to its receptor activates one major apoptotic pathway. Results from some preclinical studies suggest that classic anticancer drugs may need fas and fasL to induce apoptosis. Interestingly, stimulation of fas receptor by agonistic anti-fas monoclonal antibodies also promotes angiogenesis in murine model (Biancone et al, 1997). Thus, fas receptor stimulation by fasL might induce angiogenesis in breast cancer as well. These findings may explain why fasL expression was correlated with angiogenesis in our material. Further studies are required to confirm the possible role of apoptotic fas/fasL system in tumour neovascularisation.

In conclusion the results of this study suggest that microvessel density of primary tumour is not useful in predicting response to taxane or 5-fluorouracil based chemotherapy in advanced breast cancer.

\section{ACKNOWLEDGEMENTS}

We thank the departments of pathology of the participating institutions for providing us with tumour specimens and Ms Elina Laitinen for expert technical assistance. This study was supported by State Subsidy for University Hospitals, a research grant from Helsinki University Central Hospital (O Tynninen, T Paavonen) and Cancer Organizations of Finland (O Tynninen, $\mathrm{T}$ Paavonen).

Biancone L, Martino AD, Orlandi V, Conaldi PG, Toniolo A, Camussi G (1997) Development of inflammatory angiogenesis by local stimulation of Fas in vivo. J Exp Med 186: $147-152$

Bosari S, Lee AK, DeLellis RA, Wiley BD, Heatley GJ, Silverman ML (1992) Microvessel quantitation and prognosis in invasive breast carcinoma. Hum Pathol 23: $755-761$ 
Corle DK, Sears ME, Olson KB (1984) Relationship of quantitative estrogenreceptor level and clinical response to cytotoxic chemotherapy in advanced breast cancer. An extramural analysis. Cancer 54: 1554-1561

Folkman J (1995) The influence of angiogenesis research on management of patients with breast cancer. Breast Cancer Res Treat 36: 109-118

Gasparini G, Fox SB, Verderio P, Bonoldi E, Bevilacqua P, Boracchi P, Dante S, Marubini E, Harris AL (1996) Determination of angiogenesis adds information to estrogen receptor status in predicting the efficacy of adjuvant tamoxifen in node-positive breast cancer patients. Clin Cancer Res 2: $1191-1198$

Gasparini G, Weidner N, Bevilacqua P, Maluta S, Dalla-Palma P, Caffo O, Barbareschi M, Boracchi P, Marubini E, Pozza F (1994) Tumor microvessel density, p53 expression, tumor size, and peritumoral lymphatic vessel invasion are relevant prognostic markers in node-negative breast carcinoma. $J$ Clin Oncol 12: 454-466

Hansen S, Grabau DA, Sørensen FB, Bak M, Vach W, Rose C (2000) The prognostic value of angiogenesis by Chalkley counting in a confirmatory study design on 836 breast cancer patients. Clin Cancer Res 6: 139-146

Jacquemier J, Penault-Llorca F, Viens P, Houvenaeghel G, Hassoun J, Torrente M, Adelaide J, Birnbaum D (1994) Breast cancer response to adjuvant chemotherapy in correlation with erbB2 and p53 expression. Anticancer Res 14: 2773-2778

Jacquemier JD, Penault-Llorca FM, Bertucci F, Sun ZZ, Houvenaeghel GF, Geneix JA, Puig BD, Bardou VJ, Hassoun JA, Birnbaum D, Viens PJ (1998) Angiogenesis as a prognostic marker in breast carcinoma with conventional adjuvant chemotherapy: a multiparametric and immunohistochemical analysis. J Pathol 184: $130-135$

Medri L, Nanni O, Volpi A, Scarpi E, Dubini A, Riccobon A, Becciolini A, Bianchi S, Amadori D (2000) Tumor microvessel density and prognosis in node-negative breast cancer. Int J Cancer 89: 74-80

Miller AB, Hoogstraten B, Staquet M, Winkler A (1981) Reporting results of cancer treatment. Cancer 47: 207-214

Muss HB, Thor AD, Berry DA, Kute T, Liu ET, Koerner F, Cirrincione CT, Budman DR, Wood WC, Barcos M, Henderson IC (1994) c-erbB-2 expression and response to adjuvant therapy in women with node-positive early breast cancer. N Engl J Med 330: 1260-1266

Paulsen T, Aas T, Børresen AL, Varhaug JE, Lønning PE, Akslen LA (1997) Angiogenesis does not predict clinical response to doxorubicin monotherapy in patients with locally advanced breast cancer. Int J Cancer 74: 138 140

Protopapa E, Delides GS, Révész L (1993) Vascular density and the response of breast carcinomas to mastectomy and adjuvant chemotherapy. Eur Cancer 29A: $1391-1393$

Sjöström J, Blomqvist C, Heikkilä P, von Boguslawski K, Räisänen-Sokolowski A, Bengtsson NO, Mjaaland I, Malmström P, Ostenstadt B, Bergh J, Wist E, Valvere V, Saksela E (2000) Predictive value of p53, mdm-2, p21, and mib-1 for chemotherapy response in advanced breast cancer. Clin Cancer Res 6: 3103-3110

Sjöström J, Blomqvist C, Mouridsen H, Pluzanska A, Ottosson-Lönn S, Bengtsson NO, Østenstad B, Mjaaland I, Palm-Sjövall M, Wist E, Valvere V, Anderson H, Bergh J (1999) Docetaxel compared with sequential methotrexate and 5-fluorouracil in patients with advanced breast cancer after anthracycline failure: a randomised phase III study with crossover on progression by the Scandinavian Breast Group. Eur J Cancer 35: 11941201
Sjöström J, Blomqvist C, von Boguslawski K, Bengtsson N-O, Mjaaland I, Malmstöm P, Østenstadt B, Wist E, Valvere V, Takayama S, Reed JC, Saksela E (2002a) The predictive value of bcl-2, bax, bcl-xl, bag-1, fas and fasL for chemotherapy response in advanced breast cancer. Clin Cancer Res 8: $811-816$

Sjöström J, Collan J, von Boguslawski K, Franssila K, Bengtsson N-O, Mjaaland I, Malmström P, Østenstadt B, Wist E, Valvere V, Bergh J, SkiöldPetterson D, Saksela E, Blomqvist C (2002b) C-erbB-2 expression does not predict response to docetaxel or sequential methotrexate and 5-fluorouracil in advanced breast cancer. Eur I Cancer 38: 535-542

Sweeney CJ, Miller KD, Sissons SE, Nozaki S, Heilman DK, Shen J, Sledge Jr GW (2001) The antiangiogenic property of docetaxel is synergistic with a recombinant humanized monoclonal antibody against vascular endothelial growth factor or 2-methoxyestradiol but antagonized by endothelial growth factors. Cancer Res 61: 3369-3372

Toi M, Inada K, Suzuki H, Tominaga T (1995) Tumor angiogenesis in breast cancer: its importance as a prognostic indicator and the association with vascular endothelial growth factor expression. Breast Cancer Res Treat 36: $193-204$

Toi M, Kashitani J, Tominaga T (1993) Tumor angiogenesis is an independent prognostic indicator in primary breast carcinoma. Int J Cancer 55: $371-374$

Tynninen O, von Boguslawski K, Aronen HJ, Paavonen T (1999) Prognostic value of vascular density and cell proliferation in breast cancer patients. Pathol Res Pract 195: 31-37

Van Hoef ME, Knox WF, Dhesi SS, Howell A, Schor AM (1993) Assessment of tumour vascularity as a prognostic factor in lymph node negative invasive breast cancer. Eur J Cancer 29A: $1141-1145$

Vartanian RK, Weidner N (1994) Correlation of intratumoral endothelial cell proliferation with microvessel density (tumor angiogenesis) and tumor cell proliferation in breast carcinoma. Am J Pathol 144: 1188-1194

Vincent-Salomon A, Carton M, Zafrani B, Freneaux P, Nicolas A, Massemin B, Fourquet A, Clough K, Pouillart P, Sastre-Garau X (2001) Long term outcome of small size invasive breast carcinomas independent from angiogenesis in a series of 685 cases. Cancer 92: 249-256

Weidner N, Folkman J, Pozza F, Bevilacqua P, Allred EN, Moore D, Meli S, Gasparini G (1992) Tumor angiogenesis: a new significant and independent prognostic indicator in early-stage breast carcinoma. J Natl Cancer Inst 84: $1875-1887$

Weidner N, Semple JP, Welch WR, Folkman J (1991) Tumor angiogenesis and metastasis - correlation in invasive breast carcinoma. $N$ Engl J Med 324: $1-8$

Willsher PC, Pinder SE, Gee JM, Ellis IO, Chan SY, Nicholson RI, Blamey RW, Robertson JF (1998) C-erbB2 expression predicts response to preoperative chemotherapy for locally advanced breast cancer. Anticancer Res 18: $3695-3698$

Zambetti M, Oriana S, Quattrone P, Verderio P, Terenziani M, Zucali R, Valagussa P, Bonadonna G (1999) Combined sequential approach in locally advanced breast cancer. Ann Oncol 10: $305-310$ 